\title{
O livro de mesa como dispositivo de reconhecimento sociocultural
}

\section{Coffee table book as anapparatus for sociocultural identity}

\section{Francisco S. Barbosa da Silva}

Doutor e mestre em Comunicação e Semiótica (PUC-SP), jornalista, escritor e editor. É coautor de "Sobre Fibras e Gente (2015) e de "Carnes e Churrasco, por Marcos Bassi - Entrevista a Chico Barbosa" (2012), prêmio "Gourmand World Awards 2013". É autor de "A chave do Sucesso - Como a Audi se Tornou Cult" (2004), Prêmio Jabuti em 2005, categoria Projeto/Produção Editorial. <cb@cbnews.com.br>

\section{RESUMO}

Este artigo tem como objetivo analisar o livro de mesa (também chamado de coffee table book) como parte de uma rede de dispositivo de reconhecimento sociocultural. A hipótese considerada é a de que, por serem dotados, sobretudo, de apelos visuais, esses títulos, a princípio, são colocados em evidência no ambiente como um recurso meramente decorativo, mas, de fato, o que se pretende é valer-se de tais obras emblemáticas para promover uma série de representações envolvendo aspectos estéticos, e assim revelar a persona de quem os exibe. $\mathrm{O}$ objeto, aqui simbolizado pelas obras da editora alemã Taschen, é interpretado a partir do conceito de dispositivo de Agamben. Para destacar as especificidades nos livros que despertam reconhecimento sociocultural, recorremos a estudos sobre o sistema de objetos, consumo, luxo e capital cultural. As obras são analisadas ainda como mercadorias com valores simbólicos e fetichistas.

Palavras-chave: Livro de mesa. Coffee table book. Taschen. Dispositivo.

\begin{abstract}
The objective of this paper is to analyze coffee table books as one of a series of apparatuses for sociocultural identity. The thesis under consideration is that, to begin with, since they are especially laden with visual appeal, these works are arranged in the ambience for merely decorative purposes but, in fact, the intention is that they serve as emblems of a variety of esthetic signals, and thus reveal the persona of the one who has put them on display. The object, which is symbolized here by works from Germany's Taschen publishing company, is interpreted according to Agamben's apparatus concept. In order to highlight the specific elements in the books that give rise to sociocultural identity, we examined studies on object systems, consumer habits, luxuries, and cultural capital. The works are also analyzed as goods with symbolic and fetish value.
\end{abstract}

Keywords: Coffee table book. Taschen. Apparatus.

\section{Livro-espetáculo: sintoma do seu tempo}

O coffee table book, também chamado de livro de mesa, pode desempenhar papel de dispositivo (Agamben, 2010) de reconhecimento sociocultural, tendo em vista os processos de subjetivação que desencadeia ao interagir estrategicamente em ambientes privados ou de circulação pública. 
Coffee table book é um termo utilizado pelo mercado, às vezes a contragosto, para definir o livro que se destaca, sobretudo, pela apresentação e pela utilização que se faz dele. Por ser obra que privilegia o aspecto visual, amplamente ilustrada e com rigoroso acabamento artístico e luxuoso, fica à mostra, e não acomodada, esquecida ou até escondida em estantes, como costuma ocorrer com os demais títulos em papel. Vem dessa vocação exibicionista, por sinal, a origem controversa do seu nome. Embora tenha equivalência no português ao referido livro de mesa - convenhamos, também esclarecedora do objeto e de seu habitat -, tal denominação tende a ser empregada comumente em inglês até em países de outras línguas que não o anglo-saxão, como o Brasil, país que, até onde se sabe, nem sequer dispõe de uma coffee table no seu mobiliário. De todo modo, seja como for nomeado, o que aqui nos interessa é o fato de que o "objeto" é colocado em destaque nas áreas sociais (figura 1), fazendo as vezes de um recurso aparentemente decorativo, mas, no fundo, pelo seu poder simbólico' (Bourdieu, 2006), muitas vezes o que se pretende com a obra, ali, é comunicar uma série de representações envolvendo apuro estético, bom gosto, estilo, interesses culturais e, assim, revelar a persona de quem o exibe. Para efeito deste trabalho, seguiremos "o lado" do consumidor brasileiro que, em oposição a quem produz, elege a expressão coffee table book, considerando-a apta a enunciar o contexto de inserção desses produtos na sociedade, nosso principal foco de interesse.

Dado o preconceito que cerca esse tipo de livro, poucos se dão conta da especificidade do seu segmento, supondo-se que ele seja composto apenas de produtos feitos para repousar como escultura sobre a mesa de uma sala ou numa de recepção tal qual um simples objeto de decoração. Também é, ou pode ser, mas não só. Trata-se de um campo editorial que abriga o conhecimento e o entretenimento, e que, pela sua natureza, favorece reflexão a respeito do mundo da cultura, da imagem e da mídia no qual vivemos. Extremismos conceituais à parte, sabemos que "ao lado da fascinação da cultura de massa, dos seus momentos que fazem brilhar também diversos produtos muito ruins, há ainda outro tipo de fascinação, que vem dos bons produtos" (Prokop, 1986, p. 154). Os coffee table books ou as obras correspondentes, portanto, podem ser consideradas de credibilidade editorial, desde que concebidas com tal propósito.

1 Termo criado pelo sociólogo francês Pierre Bourdieu para definir, em linhas gerais, um poder invisível que não se exerce por meio de força nem economicamente, mas que é representado por algo ou alguém. 
- Figura 1: A mbiente que compõe o livro 100 Interiores Around the World, da Taschen: sobre a mesa, os livros no papel de coffee table books, revelando a persona da dona da casa.

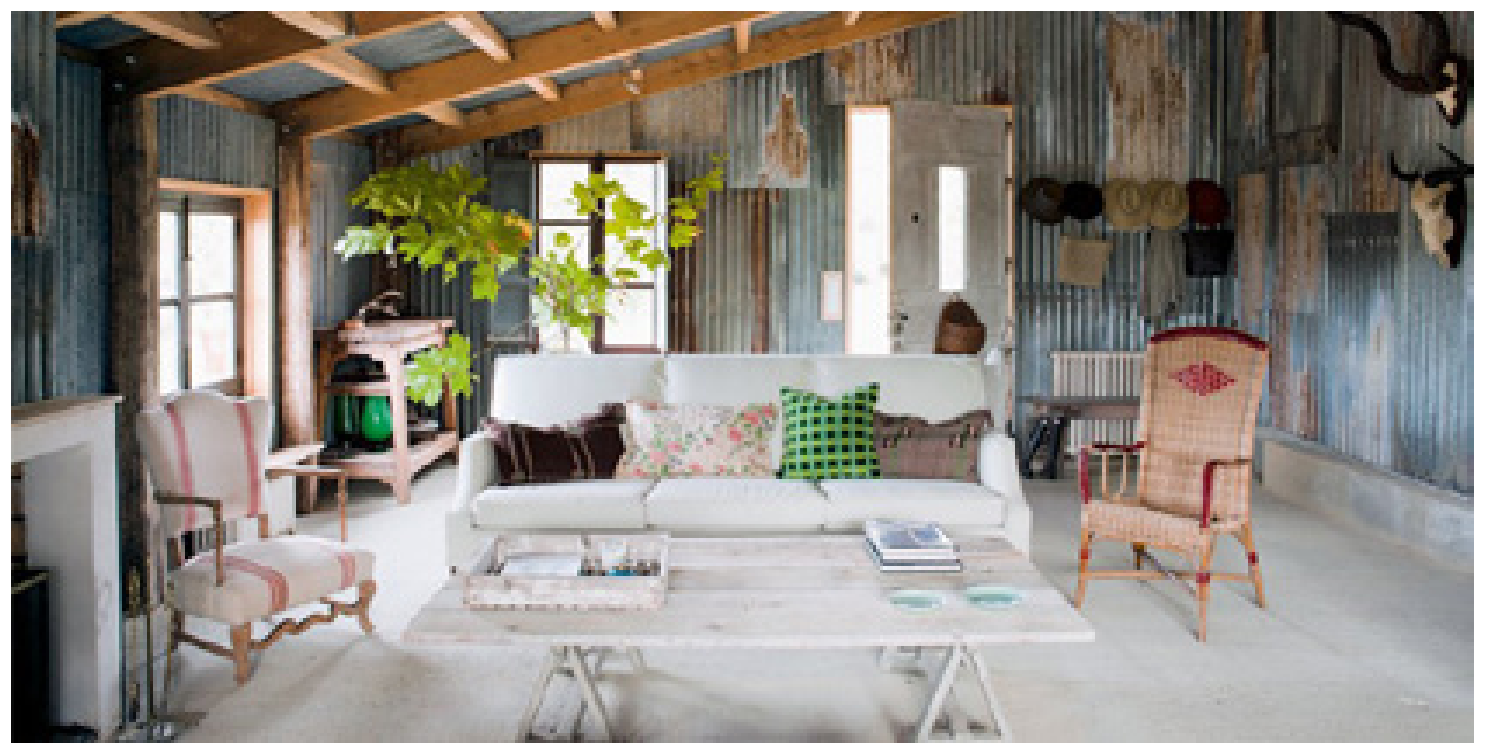

O livro nem sempre nasce coffeetable book, ou seja, ele não é criado apenas para ser visto tal qual um objeto; o livro torna-se coffee table book de acordo com a sua aparência - o que explica a sua exposição e a fetichização que desperta. Entretanto, parece natural que, a partir do crescimento da procura por esse tipo de obra, as (tidas como boas) editoras, propositalmente, passaram a contemplar diferentes interesses de público, produzindo títulos que têm, ao mesmo tempo, apelo editorial e estético, atendendo, assim, tanto a quem quer consultá-los como também a quem quer apenas apreciá-los visualmente, indiferente ao conteúdo. Com formato fora do convencional, permeado por fotografias, esses exemplares trazem pequena quantidade de texto, tratam os assuntos de forma leve e envolvente e se convertem em item de apreciação, principalmente visual, mas também tátil. Por essas particularidades, acabam sendo utilizados como parte de uma rede de dispositivo em ambientes sociais, atraindo a atenção do observador circunstancial, seja para manuseá-los, seja para apenas contemplálos. Embora possam ter aspecto que remeta a um adorno, e isso por si só não os tornaria um item cultural menor, são produtos concebidos para serem reconhecidos como livros no sentido clássico da expressão, vendidos em livrarias, sem pretender associar-se aos livros de artista ou experimentais. Mais do que enfeite, se pretendem um canal de comunicação.

Livro bem-acabado e belo, é notório, existe desde os primórdios, da fase genuinamente artesanal à da indústria editorial, cada época utilizando os 
recursos e o conhecimento que lhe eram possíveis. Nascido na Idade Antiga como um produto exclusivo, notoriamente experimental, como toda invenção que tenta se firmar, o livro vem testando suportes e apresentações que se intercalam no decorrer dos tempos, de maneira a torná-los mais práticos e, muitas vezes apenas como efeito secundário, também mais atraentes. Os monastérios, casas religiosas e igrejas foram, digamos, sua escola fundamental. "A Bíblia significou o maior treinamento para o suporte do livro da história" (Paiva, 2010, p. 30). Durante a sua trajetória, em outros corpos, estáticos ou flexíveis, o livro ou seu equivalente foi composto por (e em) pedra, madeira, argila, papiro, pergaminho até chegar no papel, de onde está migrando para as telas digitalizadas de computadores e dispositivos eletrônicos afins. Salvo a época atual, que prima também por outros atrativos, em todas as demais fases o objetivo das mudanças foi tornar a obra mais fácil de ser consultada e carregada e também mais bela e digna de ser reverenciada, nos tempos remotos, ou consumidas, nos tempos atuais.

Assim, o produto coffee table book é sintoma do seu tempo, a saber, a contemporaneidade, quando "o espetáculo não é um conjunto de imagens, mas uma relação social entre pessoas, mediada por imagens" (Debord, 2009, p.14) e quando se "vê manifestar-se o 'direito' às coisas supérfluas para todos, o gosto generalizado pelas grandes marcas, o crescimento de consumos ocasionais [...], uma relação menos institucionalizada, mais personalizada, mais afetiva com os signos prestigiosos" (Lipovetsky e Roux, 2005, p.16). A despeito de eventuais virtudes e defeitos, bem ou mal essas obras representam ou dialogam com pelo menos alguns aspectos sociais, econômicos, tecnológicos de sua época - a bem da verdade um fenômeno que ocorre com boa parte das criações culturais, independentemente do campo de atuação e de seus atores e objetos. O produto coffee table book explica-se e pode justificar-se pelo que traz de apresentação, física e das imagens que ostenta, traduzindo, revelando, sugerindo, antecipando ou revalidando as características de seus dias, assim como outras obras foram porta-vozes de um modo de ser de outros períodos e espelhavam seu momento histórico, social, econômico, cultural e tecnológico.

Como os coffee table books são mais uma forma de apresentar o livro socialmente do que propriamente uma categoria editorial, uma vez que obras de diferentes perfis podem se candidatar a receber os holofotes do ambiente, uma genealogia desses títulos teria que se deter não em quando foram concebidos, mas sim quando passaram a entrar em cena, no sentido de serem expostos como livros que são, ou como parte integrante de uma rede dispositivo de conhecimento sociocultural, ou como uma obra com apelos estéticos, ou mesmo 
como um objeto que desperta os aspectos fetichista enquanto mercadoria. Ou tudo simultaneamente. Uma hipótese a ser considerada é a de que o uso do livro como objeto de reconhecimento social tenha sido incorporado à vida contemporânea de forma sistemática a partir dos anos 1960, quando arte, mídia e consumo se uniram explicitamente para ganhar o mercado.

O tipo de livro que compõe o corpus desta pesquisa, entretanto, surgiu algumas décadas mais tarde, em 1980, pelas mãos da Taschen, editora alemã criada na cidade de Colônia. Nascida como uma despretensiosa loja de quadrinhos e catálogos, a marca se tornou referência quando, a partir de 1984, começou a publicar livros de arte a preços convidativos, sem abrir mão da qualidade gráfica. Em poucos anos ganhou corpo editorial e passou a se destacar no mercado com produtos que mostravam a "cumplicidade do pósmodernismo com a lógica do mercado e do espetáculo" (Anderson, 1999, p. 77). Desde então, angariou reconhecimento pelo tratamento estético e pela irreverência temática de seus produtos, demonstrando que "as superfícies adquirem cada vez mais importância no nosso dia-a-dia" (Flusser, 2007, p. 102). Não se trata da única, tampouco da primeira editora a produzir livros que são usados como coffee table books, mas é a que mais estardalhaço faz no mercado.

A Taschen tem se notabilizado por oferecer produtos que privilegiam a imagem, abordando as áreas de arte, consumo, estilo de vida e cultura pop, sendo seu ponto forte os títulos tidos como mais apelativos que envolvem comportamento ou artistas pouco convencionais. Em suma, livros convidativos à consulta, de fácil assimilação visual e invariavelmente com apelo artístico, sendo os chamados "Collectors Editions" bem valiosos. "A imagem é certamente mais imperativa do que a escrita, impõe a significação de uma só vez, sem analisá-la, sem dispersá-la" (Barthes, 1982, p. 132).

\section{Decodificando o dispositivo}

O termo dispositivo carrega uma série de interpretações e acepções associadas ao contexto em que é empregado. Atualmente, a expressão tem um caráter mais tecnológico, em razão da proliferação dos equipamentos eletrônicos, como telefones, tablets, MP3 e afins. Também pode ter conotação jurídica, militar e, entre tantas outras, com uma interpretação mais filosófica e sociológica, assim tornada objeto de estudos pelo intelectual francês Michael Foulcault. Para o autor, dispositivo é o conjunto que engloba discursos, instituições, organizações arquitetônicas, decisões regulamentares, leis, medidas administrativas, enunciados científicos, proposições filosóficas, morais, 
filantrópicas. "Em suma, o dito e o não dito são elementos do dispositivo. $\mathrm{O}$ dispositivo é a rede que se pode estabelecer entre estes elementos" (Foucault, 1995, p. 244).

A partir daí, Foulcault se propõe a demarcar a natureza que nasce da relação de elementos tão diferentes entre si, esclarecendo que tal discurso pode aparecer como um programa institucional, como elemento que permite justificar e mascarar uma prática, podendo ainda funcionar como reinterpretações dessa prática, conferindo-Ihe acesso a um novo campo de racionalidade. "Em suma, entre estes elementos, discursivos ou não, existe um tipo de jogo, ou seja, mudanças de posições, modificações de funções, que também podem ser muito diferentes" (Foucault, 1995, p. 244). Ampliando a interpretação sobre esse fenômeno, Foucault entende dispositivo como um tipo de formação que, em determinado momento histórico, teve como função principal responder a uma urgência. "O dispositivo tem, portanto, propósito estratégico dominante" (Foucault, 1995, p. 244). Cabe destacar essa questão estratégica, gênese comum entre os dispositivos em meio a elementos heterogêneos - e ponto em que iremos nos deter para analisar os coffee table books como objetos envoltos em representações.

O intelectual italiano Giorgio Agamben (2010), reconhecendo ser o dispositivo um termo técnico decisivo em Foulcault, se dispõe a rever o entendimento de sua utilização. Esquematicamente, articula uma divisão do existente em dois grupos ou classes: os seres viventes (ou as substâncias) e os dispositivos em que esses são incessantemente capturados.

Generalizando posteriormente a já bastante ampla classe dos dispositivos foulcaltianos, chamarei literalmente de dispositivo qualquer coisa que tenha de algum modo a capacidade de capturar, orientar, determinar, interceptar, modelar, controlar e assegurar os gestos, as condutas, as opiniões e os discursos dos seres viventes. Não somente prisões, manicômios, o Panóptico, as escolas, a confissão, as fábricas, as disciplinas, as medias jurídicas etc, cuja conexão com o poder é num certo sentido evidente, mas também a caneta, a escritura, a literatura, a filosofia, a agricultura, o cigarro, a navegação, os computadores, os telefones celulares e - por que não - a própria linguagem, que talvez seja o mais antigo dos dispositivos, em que há milhares e milhares de anos um primata provavelmente sem se dar conta das consequências que se seguiriam - teve a inconsciência de se deixar capturar (Agamben, 2010, p. 4041) (grifo nosso). 
Entre o que Agamben chama de seres viventes e os dispositivos, fruto da relação corpo a corpo de ambos estaria o sujeito ou, precisamente, os vários sujeitos que emergem desses contatos. "Um mesmo indivíduo pode ser o lugar dos múltiplos processos de subjetivação: o usuário de telefones celulares, o navegador da internet, o escritor de contos, o apaixonado por tango, o não-global" (Agamben, 2010, p. 41) - ou, para trazer o foco para a pesquisa, o sujeito e os processos de subjetivação produzidos pelo coffee table book. No entendimento de Agamben, o crescimento no número de dispositivos e a proliferação de processos de subjetivação produzem a impressão de que a categoria da subjetividade perde consistência. "Mas se trata, para ser preciso, não de um cancelamento ou de uma superação, mas de uma disseminação que leva ao extremo o aspecto do mascaramento que sempre acompanhou toda a identidade pessoal" (Agamben, 2010, p. 40-41).

Neste estudo nos interessa empregar a compreensão mais abrangente que Agamben faz da denominação dispositivo, adotada já a partir do início deste texto, porque acreditamos que os coffee table books trazem uma referência ideológica implícita em suas formas, estilos e propostas editoriais, capazes de, como comentou Agamben (2010, p. 40) acima, exercer ao menos uma das funções por ele descritas: "capturar, orientar, determinar, interceptar, modelar, controlar e assegurar os gestos, as condutas, as opiniões e os discursos dos seres viventes", aqui, reforçamos, entendidos tanto por quem os mostra como para quem os observa. Como iremos discutir adiante, os coffee table books são dotados de especificidades de reconhecimento público, passíveis de valoração."A aparência torna-se importante - sem dúvida, importantíssima - na consumação do ato da compra enquanto ser. O que é apenas algo, mas não parece um 'ser', não é vendável. O que parece ser algo é vendável" (Haug, 1997, p. 26-27). A partir da classificação do valor de um produto (Marx, 1897, seção 3,) a despeito do seu "Valor de Uso" (informar, entreter), essas obras tendem a ter alto "Valor de Troca" (mercantil), apoiadas justamente nas suas características "corporais", como materiais nobres e emprego de mão de obra especializada. Instauram um outro "Valor de Culto" (Benjamin, 2011), diferente daquele que acompanha o livro comum, e são repletos de "Valor de Exposição" (Benjamin, 2011), enquanto objetos de consumo associado à sociedade contemporânea. E, livros que são, pelo conteúdo propriamente, são dotados do que se convencionou chamar de "Valor Imaterial" (Gorz, 2005).

O coffee table book não é tão somente um livro com características físicas que o distinguem dos outros livros, mas o fato de ter esse tipo de aparência/corpo promove processos de subjetivação a ela correlatos, com todas as implicações 
culturais. Se todo corpo existe na relação com os ambientes por onde circula, segundo a Teoria Corpomídia (Katz, 2005), o corpo do coffee table book revela o trânsito corpo-ambiente que o constitui. Seu propósito está, primeiramente, no subliminar, no que se esconde e ao mesmo tempo se revela no seu modo de existir, ou seja, na sua aparência. Esse corpo-livro, com formato e proporções próprios, é corpomídia2 de uma vocação específica: estimular os sentidos para uma fruição estética. "O meio é a mensagem” (McLuhan, 2007), no sentido de que apenas sua exposição e consonância com o ambiente já anuncia esta sua vocação. Mesmo quando não aberto e folheado, o coffee table book, como enunciado, "cumpre sua função de existência que pertence, exclusivamente, aos signos" (Foucault, 2012, p.105), dada a cadeia de elementos que o envolvem como dispositivo.

O intelectual francês Gille Deleuze (1990) entende o termo foulcautiano como "uma espécie de novelo ou meada, um conjunto multilinear", de que, acreditamos, podemos nos valer para interpretar os elementos que envolvem o coffee table book enquanto parte de uma rede de dispositivos. "Os dispositivos têm, então, como componentes linhas de visibilidade, linhas de enunciação, linhas de força, linhas de subjetivação, linhas de ruptura, de fissura, de fratura que se entrecruzam e se misturam" (Deleuze, 1990, p. 155-161).

\section{Coreografia de interações lineares}

A partir dessas referências, cabe-nos investigar que linhas passíveis de subjetivação podemos identificar no coffee table book, enquanto parte de uma rede de dispositivos, para além do que está explicitamente contido em um livro, ou seja, seu conteúdo, previamente estabelecido por um contrato de comunicação (Charaudeau, 2006) subentendido com o leitor, que, neste caso, sabe se tratar de obra sui generis, com características específicas, de forte apelo à visualidade. Por compor uma rede de dispositivo a ser exposto, que interage com o entorno, destacam-se os aspectos inerentes à sua apresentação, relacionados com sensações despertadas a partir da sua materialidade, que pesponta originalidade, bom gosto associado à referência cultural, valor, luxo

2 O conceito de corpomídia refere-se ao modo do corpo existir em relação aos ambientes com a característica de ser mídia de um processo de trocas incessantes. Não se trata de um corpo por onde a informação entra, é processada e, depois, devolvida ao ambiente. De acordo com a Teoria Corpomídia, a informação entra e transforma-se enquanto vai modificando as informações com as quais se põe em contato. O corpo está, a cada instante, revelando esse processo, sendo mídia de si mesmo nesse processo. 
e, por extensão, prestígio social. O intelectual italiano Mario Perniola afirma que é justamente no plano do sentir que a nossa época exerceu seu poder, o que nos permite defendê-la como uma época estética. "Não por ter uma relação privilegiada e direta com as artes, mas essencialmente porque o seu campo estratégico não é o cognitivo, nem o prático, mas o de sentir, o da aisthesis" (Perniola, 1991, p.11).

Partimos do pressuposto de que ocorre uma comunicação entre coffee table books e seu público. Os objetos são uma forma de as pessoas se definirem socialmente, sinalizarem o que são e o que não são. "Ora são as joias que assumem esse papel, ora são os móveis que usamos em nossas casas, ou os objetos pessoais que carregamos conosco, ou as roupas que usamos" (Sudjic, 2010, p. 21). De certa maneira, os coffee table books, que, quando expostos tendem a ser parte de uma complexa coreografia de interações, também podem, a partir de suas formas, acabamento e temas, revelar muito de quem os expõem.

Aqui seguem algumas possibilidades de como os coffee table books podem atuar:

\section{Como objeto de consumo}

À nossa volta, existe hoje uma espécie de evidência fantástica do consumo e da abundância, criada pela multiplicação dos objetos, dos serviços, dos bens materiais, originando como que uma categoria de mutação fundamental na ecologia da espécie humana. Para falar com propriedade, os homens da opulência não se encontram rodeados, como sempre acontecera, por outros homens, porém mais por objetos. (Baudrillard, 2010, p. 13).

Eis o contexto do nosso objeto de estudo (figura 2). O coffee table books se legitima a partir do ambiente em que está, uma diferença marcante em relação às obras que se destacam pelo que trazem no seu interior. A própria denominação é reveladora do local em que o livro fica à disposição, genericamente junto à mesa de apoio de objetos, ou seja, está associado a um momento de descontração e informalidade e a um cômodo específico, em que o "espaço é de certa maneira a liberdade real do objeto, sua função é só sua liberdade formal" (Baudrillard, 2009, p. 25). Em locais cada vez mais impessoais, funcionais, harmonizados pela ditadura do senso comum, nos quais "os objetos não se correspondem mais, comunicam; não têm mais presença singular, mas, no melhor dos casos, uma coerência de conjunto feita de sua simplificação como elementos de código e do cálculo de suas relações" (Baudrillard, 2009, p. 31), os coffee table book assumem o papel de personalizar o ambiente, transformando-se em um produto com 
nítido viés cultural. "A uma sociologia dos móveis sucede uma sociologia do arranjo" (Baudrillard, 2009, p. 32).

Na medida em que nos propusemos a perceber os coffee table books como artefato cultural vinculado ao consumo e com características estéticas, podemos entendê-lo como um objeto desprovido de funções pragmáticas relacionadas ao "uso" habitual do livro e permeado de conotações pessoais. "A posse jamais é a de um utensílio, pois este me devolve ao mundo, é sempre a de um objeto abstraído de sua função e relacionado ao indivíduo" (Baudrillard, 2009, p. 94). O intelectual e roteirista francês Jean-Claude Carriére explica que alguns afirmam haver dois tipos de livro: o que o autor escreve e o que o leitor possui."Para mim, o personagem interessante é também quem o possui. É o que se chama 'proveniência'. Tal livro pertenceu a Fulano. Se você possui um livro que provém da biblioteca de Mazarin, você possui um pedaço do rei" (Carriére, Eco, 2010, p. 97). Os coffee table books, abstraídos da sua função de livro, passam a ter a função de objetos, ainda que culturais, e jamais domésticos.

Todo objeto tem desta forma duas funções: uma que é ser utilizado, a outra que é ser possuído. A primeira depende do campo de totalização prática do mundo pelo indivíduo, a outra, um empreendimento de totalização abstrata realizada pelo indivíduo sem a participação do mundo. Essas duas razões acham-se na razão inversa uma da outra. Em última instância, o objeto estritamente prático toma um estatuto social: é a máquina. Ao contrário, o objeto puro, privado de função ou abstraído de seu uso, toma um estatuto estritamente objetivo: torna-se objeto de coleção. Cessa de ser tapete, mesa, bússola ou bibelô para se tornar "objeto". Um "belo objeto", dirá o colecionador, e não uma bela estatueta. Quando o objeto não é mais especificado pela função, é qualificado pelo indivíduo: mas neste caso todos os objetos se equivalem na posse, esta abstração apaixonada. Um apenas não basta: trata-se sempre de uma sucessão de objetos, num grau extremo, de uma 'serie total que constitui seu projeto realizado (Baudrillard, 2009, p. 94). 
Figura 2: Livros, itens culturais, assumidos como objetos de decoração.
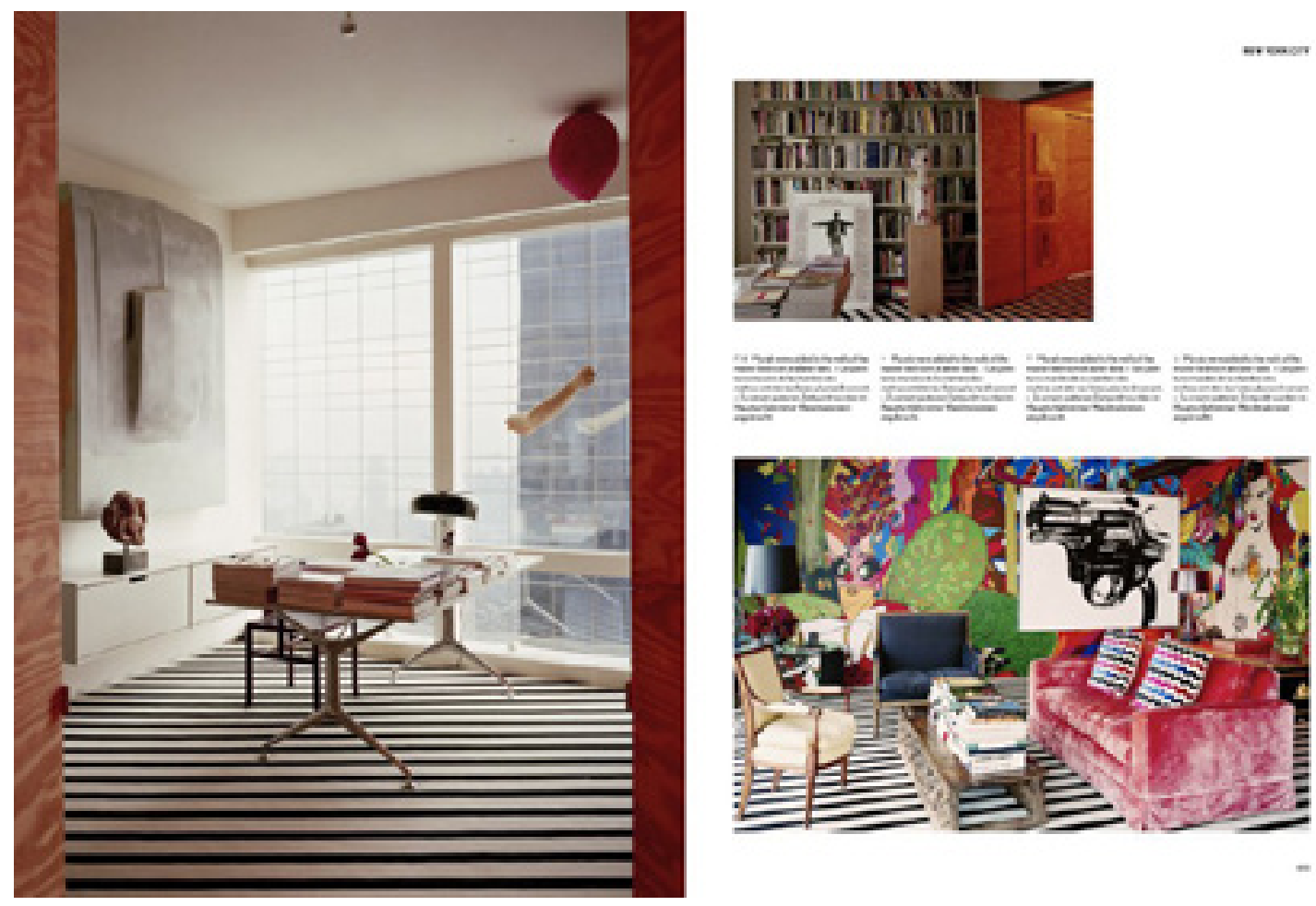

\section{Como mercadoria valiosa}

As Collector's Editions da Taschen, verdadeiros itens de colecionadores, alcançam cifras que remetem às de legítimas obras de arte. A editora promove leilões e sessões de autógrafos com seus lançamentos mais importantes, de maneira a agregar valor adicional aos produtos. Um dos casos mais midiáticos ficou por conta do livro Helmut Newton's Sumo, edição limitada de 10 mil unidades, que mede $50 \mathrm{~cm}$ x $70 \mathrm{~cm}$, pesa $30 \mathrm{~kg}$ e tem 464 páginas, cujo preço, na Europa, é 15 mil euros, tido como o mais caro livro produzido no século XX. Isto é, considerando-se uma obra comercializada em loja. Porque o exemplar número 1 (figura 3), assinado pelo autor e pelas 100 celebridades que estampam a obra, foi arrematado pela bagatela de US\$ 430 mil, tomando como base a reportagem da revista "Isto É", de 10 de dezembro de 2010. Um processo correlato ao que ocorre no mundo das artes, tomando-se como referência as reflexões do sociólogo francês Pierre Bourdieu. 
O produtor do valor da obra de arte não é o artista, mas o campo de produção enquanto universo de crença que produz o valor da obra de arte como fetiche ao produzir a crença no poder criador do artista. Sendo dado que a obra de arte só existe enquanto objeto simbólico dotado de valor se é conhecida e reconhecida, ou seja, socialmente instituída como obra de arte por espectadores dotados da disposição e da competência estéticas necessárias para a conhecer e reconhecer como tal, a ciência das obras tem por objeto não apenas a produção material da obra, mas também a produção do valor da obra ou, o que dá no mesmo, da crença no valor da obra (Bourdieu, 2010, p. 259).

Ciente da sua capacidade de agregar rendimentos aos livros, a editora alemã faz até estudo de valorização das primeiras edições de suas obras no mercado, destacando que, não importa o preço de venda, o ganho em alguns anos pode atingir $1.000 \%$. "Cultura e comércio de fundem e se alimentam de forma recíproca" (Kumar, 2006, p.155).

- Figura 3: A edição número 1 de Helmut Newton's Sumo, trazendo autógrafo do autor, foi vendida US\$ 430 mil.

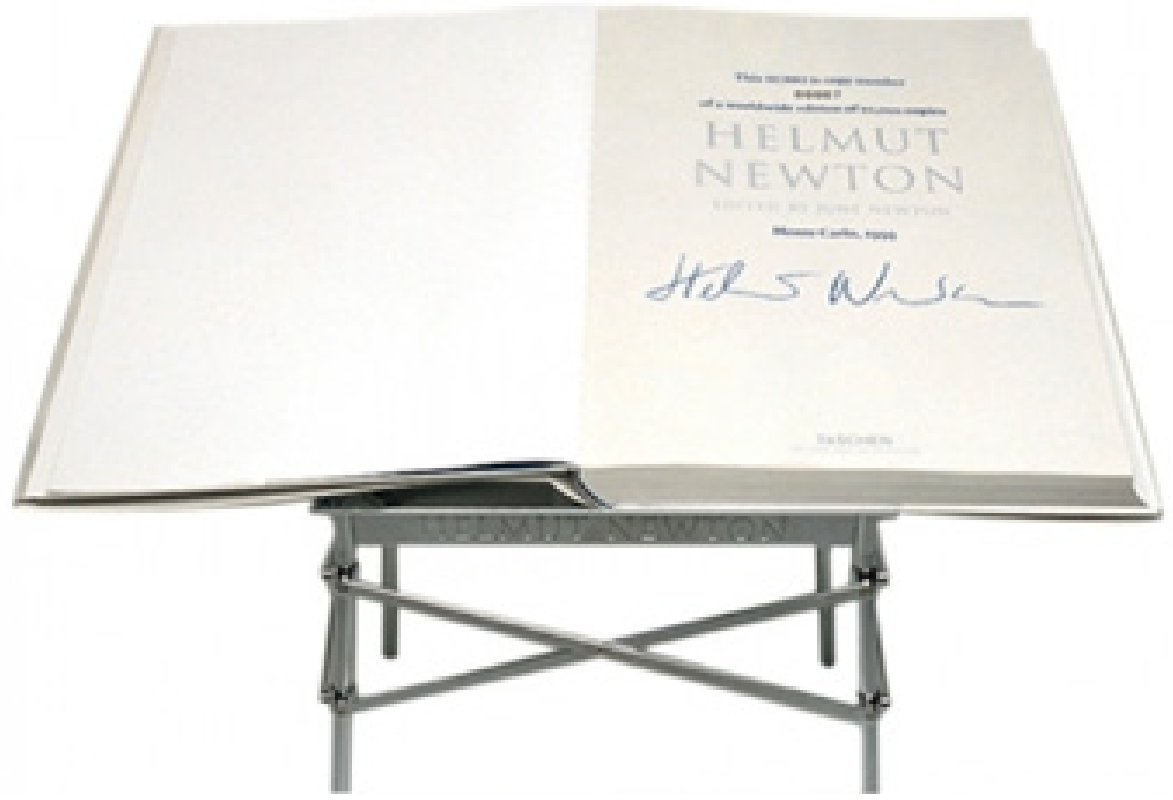




\title{
Como artefato de luxo
}

A questão da escassez a que se refere o empresário está diretamente ligada ao fator luxo, outra percepção que os coffee table books, como parte de uma rede de dispositivos, são capazes de acionar. Grosso modo, um produto é valorizado por ser um artigo raro, por usar materiais relativamente mais nobres e por empregar mão de obra altamente qualificada e maquinário de ponta. Por todos esses critérios, os coffee table books (figura 4) podem ser identificados como um produto que se posiciona como sendo de alto valor agregado, e por consequência dando um verniz de suntuosidade ao ambiente em queé mostrado e, ato contínuo, a quem os expõe. A expressão luxo não está, necessariamente, ligada a preços inacessíveis ao consumo de massa. Antigamente reservados aos círculos da burguesia rica, os produtos de luxo progressivamente "desceram à rua", para usar uma expressão cunhada por Lipovetsky.

\begin{abstract}
Em nossos dias, o setor constrói-se sistematicamente como um mercado hierarquizado, diferenciado, diversificado, em que o luxo de exceção coexiste com um luxo intermediário e acessível. Esfera daí em diante plural, o luxo "estilhaçou-se", não há mais um luxo de exceção, mas luxos, em vários graus, para públicos diversos. (Lipovetsky e Roux, 2005, p.15).
\end{abstract}

Portanto, não é preciso recorrer a livros de preços exorbitantes para que se considere os coffee table books um produto alinhado com o consumo de luxo. Até porque, muito do reconhecimento social almejado por quem se vale da exposição dessas obras para se projetar, é um processo de subjetivação, tanto para quem o mostra como para aqueles que o veem. A fim de refletir sobre os efeitos embutidos na apresentação da riqueza, Lipovetsky se vale de uma observação de Thorstein Veblen, em A Teoria da Classe Ociosa (2003): "Não apenas fazemos com que outros sintam nossa importância, não apenas aguçamos e mantemos em alerta o sentimento que eles têm dessa importância, mas também, coisa quase não menos útil, fortalecemos e preservamos todas as razões de autossatisfação" (Lipovetsky e Roux, 2005, p. 52), para concluir:

A paixão pelo luxo não é exclusivamente alimentada pelo desejo de ser admirado, de despertar inveja, de ser reconhecido pelo outro, é também sustentado pelo desejo de admirar a si próprio, de "deleitarse consigo mesmo" e de uma imagem elitista (Lipovetsky e Roux, 2005, p. 52). 
- Figura 4: Coffee table book confere ar de suntuosidade ao local onde é exposta, seja pelo tema, seja pelo acabamento, caso de Bob Willoughby: Audrey Hepburn. Photographs 1953-1966.

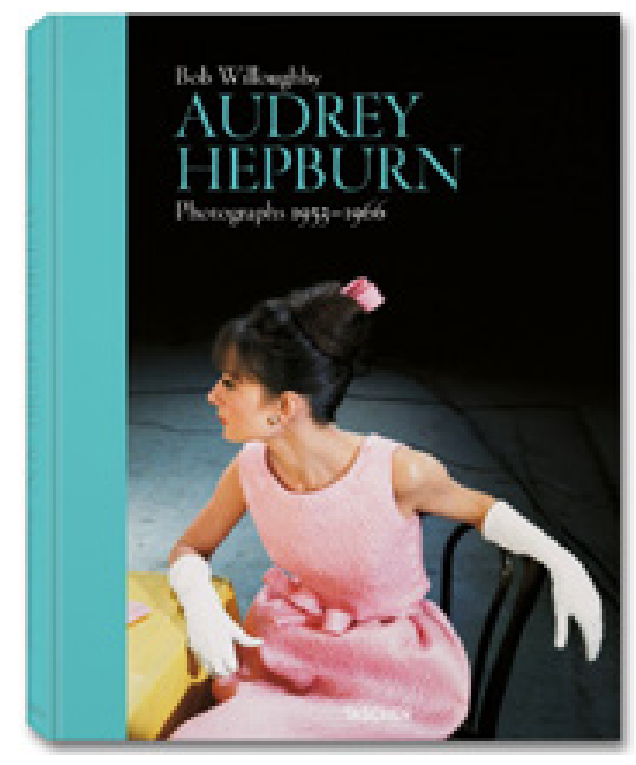

\section{Como status cultural}

Last but not least. Não se pode deixar de reconhecer o coffee table books como um livro que é, evidentemente, e portanto detentor de "capital cultural" (Bourdieu, 2006). Segundo o intelectual francês, o "capital cultural" pode existir em três estados: "incorporado", como parte integrante da pessoa, uma disposição adquirida, um habitus; "objetivado", sob a forma de um bem cultural, como livros, obras de arte; ou, "institucionalizado", por meio de diplomas e certificados de competência cultural, geralmente escolar. Por esse entendimento, os coffee table books são representantes do estado "objetivado" do "capital cultural" (figura 5) e, subliminarmente, remetem também ao estado "incorporado" de quem o expõe. Afinal, para que se decifre o estado "objetivado" é preciso ser dotado de conhecimento, aqui identificado como "capital cultural incorporado". "É um ter que se tornou ser, uma propriedade que se fez corpo e tornou-se parte integrante da 'pessoa', um habitus. Aquele que o possui 'pagou com sua própria pessoa' e com aquilo que há de mais pessoal, seu tempo" (Bourdieu, 2006, p.7475). Pode ter pago também, pelas cifras apontadas acima, com seu dinheiro. 
- Figura 5: Além de coffee table book, livros como Caravaggio - The Complete Works são detentores de "capital cultural".

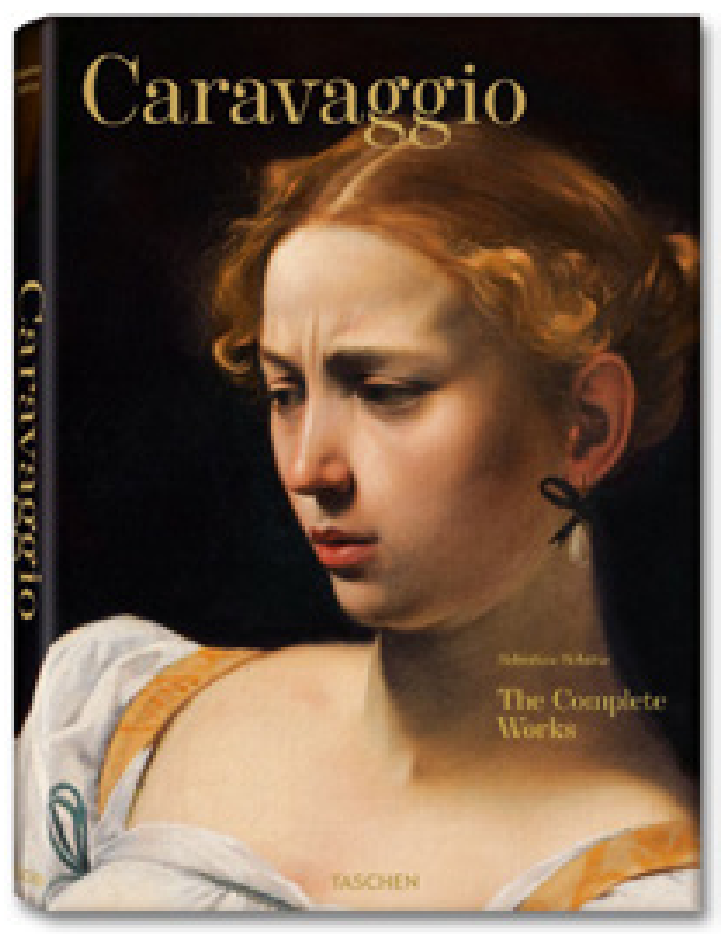

\section{Referências}

ANDERSON, Perry. As origens da pós-modernidade. Rio de Janeiro: Jorge Zahar, 1999.

AGAMBEN, Giorgio. 0 que é o contemporâneo? e outros ensaios. Chapecó: Argos, 2010.

ARQUIVO MARXISTA NA INTERNET. Disponível em: <http://www.marxists.org/ portugues/marx/1867/ocapital-v1/vol1cap01.htm\#c1s4>. Acesso em: 5 abr. 2011.

BARTHES, Roland. Mitologias. São Paulo: Difel, 1982

BAUDRILLARD, Jean. O sistema dos objetos. São Paulo: Perspectiva, 2009.

. A sociedade de consumo. Lisboa: Edições 70, 2010.

BENJAMIN, Walter. Obras escolhidas. São Paulo: Brasiliense, 2011. 
BOURDIEU, Pierre. As Regras da arte. São Paulo: Companhia das Letras, 2010.

. "Os três estados do capital cultural". In: NOGUEIRA, Maria Alice; CATANI, Afranio. Escritos de educação. Petrópolis: Vozes, 2006.

. O poder simbólico. Rio de Janeiro: Bertrand Brasil, 2006.

. A distinção: crítica social do julgamento. Porto Alegre, Zouk, 2011.

CARRIÈRE, Jean Claude; ECO, Umberto. Não contem com o fim do livro. São Paulo: Record, 2010.

CHARAUDEAU, Patrick. Discurso das mídias. Contexto: São Paulo, 2006.

DARTON, Robert. A questão do livro. Passado, presente, futuro. São Paulo: Companhia das Letras, 2010.

DEBORD, Guy. A sociedade do espetáculo. Rio de Janeiro: Contraponto, 2009.

DELEUZE, Gilles. ¿Que és un dispositivo? In: Michel Foucault, filósofo. Barcelona: Gedisa, 1990.

EAT \& TRAVEL WEEKLY. Disponível em: <http://www.taschen.com/pages/en/search/ result.1.htm?show all=catalogue\&search string=the+king+of+coffee+table+ book\&submit search=GO>. Acesso em: 10 jun. 2012.

FLUSSER, Vilém. O mundo codificado. São Paulo: Cosac Naify, 2007.

FLAVORWIRE. Disponível em <http://www.flavorwire.com/254434/the-20-mostbeautiful-bookstores-in-the-world>. Acesso em: 10 jun. 2012.

FOUCAULT, Michel. Microfísica do poder. São Paulo: Graal, 1995.

. Arqueologia do saber. Rio de Janeiro: Forense Universitária, 2012.

GORZ, André. O imaterial - conhecimento, valor e capital. São Paulo: Annablume, 2005.

HAUG, Wolfgang Fritz. Crítica da estética da mercadoria. São Paulo: Unesp, 1997.

ISTOÉ DINHEIRO. Disponível em: <http://www.istoedinheiro.com.br/noticias/42888 LIVROS+PARA+LER+E+EMOLDURAR>. Acesso em: 3 dez. 2010.

KATZ, Helena. Por uma Teoria do Corpomídia. In: GREINER, Christine. O Corpo. Pistas para estudos indisciplinares. São Paulo: Editora Annablume, 2005.

KUMAR, Krishan. Da sociedade pós-industrial à pós-moderna. Rio de Janeiro: Jorge Zahar Editor, 2006. 
LIPOVETSKY, Gilles; ROUX, Elyette. O luxo eterno. São Paulo: Companhia das Letras, 2005.

A felicidade paradoxal: ensaio sobre a sociedade de hiperconsumo. São Paulo: Companhia das Letras, 2007.

_, Gilles; SERROY, Jean. A Cultura-Mundo. A resposta a uma sociedade desorientada.São Paulo: Companhia das Letras, 2011.

MCLUHAN, Marschall. Os meios de comunicação como extensão do homem. São Paulo: Cultrix, 2007

PAIVA, Ana Paula M. A aventura do livro experimental. Belo Horizonte: Autêntica/São Paulo: Edusp, 2010.

PERNIOLA, Mario. Do sentir. Lisboa: Presença, 1993.

PROKOP, Dieter. Sociologia. São Paulo: Ática, 1986.

SUDJIC, Deyan. A linguagem das coisas. Rio de Janeiro: Intrínseca, 2010.

TASCHEN. Disponível em: <http://www.taschen.com/>. Acesso em: 5 abr. 2011.

TORIBA. Disponível em: <http://www.toribaeditora.com.br/>. Acesso em: 3 mai. 2011.

Recebido em 06 de novembro de 2014.

Aceito em 26 de fevereiro de 2015.

Endereço do Autor:

Francisco Barbosa da Silva <cb@cbnews.com.br>

CBNEWS Editora

Rua Comendador Miguel Calfat, 128, conj. 608

Vila Nova Conceição, Cep 04537 080, São Paulo - SP 